our funding of university research arising from the difference between the total value of new grants awarded in a given year and the total expenditure on all grants, new or existing, in that year. The former figure is not expenditure but new commitments extending for several years ahead, depending on the duration of the grants. In stcady conditions the figures for both new awards and annual exponditure will move together, but in practice these conditions have never ariscn.

$\begin{array}{ccccc} & 1966 / 67 & 1967 / 68 & 1968 / 69 & \begin{array}{c}\text { Estimated } \\ 1969 / 70\end{array} \\ \begin{array}{c}\text { Tutal value of ncw awards (aca- } \\ \text { demic year, October-September) }\end{array} & 1.8 & 1.2 & 0.0 & (1.0) \\ \begin{array}{c}\text { Annual exponditure (financial year, } \\ \text { April to March) }\end{array} & 0.69 & 0.89 & 0.93 & (1.2)\end{array}$

In particular, at the end of the last university quinquennium in 1967, a large proportion of existing grants terminated. It was necessary in that year, in order to sustain a steady growth in subsequent annual expenditure, to enter into an exceptionally large commitment on new awards, although this level of new commitment could not, and was never intended to be, sustained. The effect of the transition from one quinquennium to the next can be seen by comparing figures for value of new awards with those for annual expenditure on research grants, both given in millions of pounds.

'These figures show that our annual expenditure on university research grants is likely to incrense by about 75 per cent over the past 4 years from 1966 to the present time.

The second point concerns the fact that only 15 per cent of NERC's expenditure as shown in our financial statement for last year went to universities. 'These figures for university support are not, however, comparable as they stand with expenditure on research elsewhere by the council. In particular they exclude capital expendi. ture on buildings, equipment that is a regular part of the facilities of the department concerned, and supporting costs and services, all of which are provided at universities by the UGC but in our own institutes have to bo included in the NERC expenditure. In tho marine field the major part of the activities of our Research Vessel Unit, of the RRS John Murray and of the use of marino research equipment held at the Research Vessel Unit, are devoted to the needs of universities. Thus both in actual money and in research effort, our effective support of university research is a substantially larger fraction of our total expenditure than appears from the figures shown in tho financial statement under that head for accounting purposes.

Our general policy towards support of university research in the environmental seiences has boen dealt with at length in our current annual report. I need only say that we believe our support must be selective, should be guided (but not inhibited) by broad strategic objectives, and ought to link up with the programmes of our institutes whonever it is sensible and productive to do so. This brings mo to the third point, namely, the use of the so-called "success rate", that is, the ratio of funds awarded to funds applied for (which last year was just over onethird overall), as a meisure of this disappointment.

In fact, this ratio as it stands is a very unreliable index of the true extent to which our support is fislling short of the total legitimate and deserving requests. Some of the applications wo roceive, including the largest ones, are either outside our remit or are for other reasons unsuitable for support. We believe it is right to bring all of them to the attention of one or other of our grantawarding committees rather than to make the situation look more rosy by pruning them beforchand. Sometimes it is possible to find ways of achieving the desired rescarch objectives more economically, particularly by sharing expensive equipment between universities or with council establishmonts. In some cases an award is made initially for a shorter period than is requested, with the possibility of an extension if promising results are achieved. Our grant-awarding committees would be failing in their task of distributing available funds in the best interests of science if they did not give careful and critical attention to such matters.

What my council is concerued to ascertain from our grant-awarding committees is whether, at the end of the day, they fecl that a significant proportion of truly deserving applications has had to bo turned down through lack of resources. So far, I am glad to say, this has not been the case.

Yours fitithfully,

$$
\text { R. J. H. BeVERTON }
$$

Natural Environment Research Council,

Alhambra House,

London WC2.

\section{Mild Thaw on Disarmament}

Sin,-- You state, sensibly enough (Nature, 225, 211; 1970), that with rogard to strategic arms limitation, "Relations with the nuclear pigmies -Britain, France and China-are also a complication, if only because nobody ean at this stage commit hirnself to permanent restraint in nuelear weapons when there is no certainty that smaller powers will not seek to become top dogs". Certainly; but also vice versa: fow among the "nuclear pigmies" (in esse or posse) can "at this stage commit [themselves] to permanont restraint in nuclcar weapons when thero is no certainty that" the nuclear giants "will not seek to becorne top dogs" in the nuclear condominium sense. This is tho lesson of the non-proliforation treaty negotiations, and Annericans and Russians had bottor not forget it. If, as Die Welt reported two weeks ago, there is a Russian-American plan not to consider Russian medium range strategic missiles until agreement has becn reached and put into effect on intercontinental missiles, target states of those medium range strategio missiles-for example, Franco, United Kingdom, Japan, India, ete.-are unlikely to commit themselves to much "permanent restraint". This fact may well complicate regotiations at Vienna, but it will not go away merely because it is inconvenient.

$$
\text { Yours faithfully, }
$$

$$
\text { Flizabeth Youna }
$$

100 Bayswater Road,

\section{London W2.}

\section{Cover-to-cover Translation}

Sin,-Abstracts as a form of journal publication from which subscribers would order full texts as needed are mentioned by your goomagnetism correspondont (Nature, $224,750 ; 1969)$ as a possible solution for meeting cover-tocover translation problems in geophysics.

Such a scheme has boon used fur some twonty oriental vernncular journals at the Air Foreo Carnbridge Research Laboratories (AFCRL) since 1962. Abstracts are made for each single number of cach journal as received, and are circulated to AFCRL scientists. The individual scientist then requests full translation of those articles whose abstracts appear pertinent to his interests. Abstracts from any ono journal are eventually bound together and classified by subject subdivisions in order to provide a desk tool for retrospective search. One such oriental abstract translation publication which is available to the public is Acta Meteorologica Sinica; translated titles and abstracts from volume $2 \%$ (1956) through, volume 35 (1965), published as $\Lambda D 667520$. There are 360 articles abstracted in this publication, of which 69 (19 per cent) have boon requested in full translation.

Your geomagnetism correspondent also suggests that, cover-to-cover translation is not the inost economical way of bringing Russian work to the attontion of western scientists. However, AFCRL records of articles repuested 
in xerographic copy show that the cover-to-cover translation of Astronomicheskii Zhurnal is the second most heavily used journal out of a total of 57 astronomical journals used during 1964-66. Of the 119 users of these 57 astronomical journals, 29 users (15 per cent) requested 106 articles from this fully translated journal. In this ease, response time and costs would be greater for an abstract and translation cycle than for a cover-to-cover subscription, as the approximately $\$ 50$ subscription cost would hardly cover the cost of one translation.

The current difficulties encountered by the American Geophysical Union in its cover-to-cover translation programme may therefore be difficulties specific to an individual discipline rather than to all disciplines. Among factors that appear relevant are reader population sizes among different disciplines and the related number of institutions carrying programmes in these disciplines. This raises some interesting questions about the relationship of disciplines to the need for subsidizing cover-to-cover translation programmes.

\section{Yours faithfully,}

Ole V. Groos

AFCRL Research Library.

\section{Numerical Notation: Decimalization}

SrR,-The suggestion of Molyneux (Nature, 224, 1237; 1969 ) that a number such as $12,300,000$ could conveniently be written as " $1.23 \mathrm{D7}$ " and spoken as "one point two three deka seven" supports the earlier suggestion of Duffin as reported by Synge ${ }^{1}$ and differs from it only in the use of "deka" and "deci" rather than "up" and "down" to indicate respectively positive or negative powers of ten.

Such systems, however unpalatablo at first sight, lead to a great simplification in numerical notation avoiding both the need to devise ${ }^{2}$ new prefixes to indicate multiplication by powers of ten higher than the current tera $\left(10^{12}\right)$ or lower than atto $\left(10^{-18}\right)$ and also the ever present and regrettable urge to invent new names for multiples or sub-multiples of the primary Système International (SI) units. Equally, the current ambiguities ${ }^{3}$ of the terms billion and trillion could disappear from the international scenc.

The indicators "up" and "down" are probably more graphic and therefore more readily assimilated than "deka" and "deci". On the other hand, the classical derivation of the latter would render them readily recognizable in other languages: but this is not likely to be material as the indicators "up" and "down" would always be better translated into the language used for the associated numerals in order to form a unified whole for the number expressed.

We are already accustomed to breaking down numbers inte groups of three numerals and this facility could be retained by using powers of 10 in multiples of three only, thus

$12,300,000$ would be said as "twelve point three up six",

$1,230,000$ would be said as "one point two three up six".

but 123,000 would be said as "one hundred and twenty-three up three".

Yours faithfully,

F. W. Derwent

National Coal Board,

Ashby Road,

Stanhope Bretby,

near Burton-upon-Trent.

'Synge, J. I.,, Relativity: the General Theory, 421 (North-Holland Publishing Co., 1960).

2 Derwent, F. W., and Oakland, W. H., Nature, 220, 311 (1968).

suckow, F. W., The Directot, 18, 390 (1966).

\section{University News}

Mr Denis R. Towill has been appointed to the newly established chair in engineering production in the University of Wales Institute of Science and Technology.

\section{Appointments}

Philip E. Culbertson has been designated director of the Advanced Manned Missions Program in the National Aeronautics and Space Administration's Office of Manned Space Flight.

\section{Announcements}

The Neill Prize of the Royal Society of Edinburgh for 1967-69 has been awarded to Dr Ann R. Sanderson for her contributions to taxonomic zoology.

The president and council of the Royal Astronomical Society have made the following awards: the Gold Medal to Dr Horace W. Babcock, director of the Mount Wilson and Mount Palomar Observatories; the Eddington Medal to Professor Chushiro Hayashi, professor of physies, Kyoto University.

ERratum. In the paper "Genetics of NADP Isocitrate Dehydrogenase in Paramecium aurelia" (Nature, 225, $181 ; 1970$ ), line 16 on page 182 should read "heterozygote pattern $\left(\mathrm{IDH}_{m} 1-2\right)$ is consistent with".

Erratum. In the article "The Moon at Houston" (Nature, $225,321 ; 1970)$, the second sentence under the sub-heading Chemical Composition on page 326 should read: "Of the ninety-two elements in the periodic table, results are now available for seventy-nine".

\section{Sabbatical Itinerants}

In the hope of providing some practical assistance in the good cause of mobility between laboratories, Nature advertises the needs for housing of families about to take up periods of sabbatical leave. To begin with, no charge will be made for advertisements like this. It is hoped that a period of experiment will show what form these advertisements could most usefully take and whether they are effective.

Vacant: House in London, Ontario, Canada, for 12 months from mid-August 1970. Fully furnished, 4 bedrooms, 2 bathrooms, living room, dining room, kitchen, den, playroom, utility room. All necessary appliances, linen, dishes, etc. On 100 foot $\times 150$ foot lot about 1 mile from University of Western Ontario. Please contact Professor Miles H. A. Keenleyside, Department of Zoology, University of Western Ontario, London, Canada.

Vacant: Large 3-bedroom, well furnished flat in Brooklyn, New York, with modern kitchen. Rapid transit time 30 minutes to mid-Manhattan. Opposite Park, Botanic Gardens, Public Library and Museum. For 9-12 months from September 1, 1970. $\$ 215 /$ month. Please contact $\mathbf{R}$. Pollack, 135 Eastern Parkway, Brooklyn, New York 11238.

Wanted: Furnished house or flat for New Zealand lecturer and family, 3 double bedrooms minimum, from beginning of March to mid-April, in Oxford, Wantage area. Please contact Dr J. Loutit, MRC Molecular Genetics Unit, Department of Molecular Biology, University of Edinburgh, King's Buildings, Mayfield Road, Edinburgh EH9 3JR. 